\title{
Resenha: \\ Da Palavra ao Gesto, de Claudine Haroche
}

Caroline Adriana Mendes Burach ${ }^{1}$

... dans un sens, on peut dire que l'effet de la démocratie n'est point précisément de donner aux hommes certaines manières, mais d'empêcher qu'ils n'aient des manières ${ }^{2}$. (TOCQVILLE,1990, p. 185)

A proposição de uma reflexão clara a respeito das políticas europeias da França, para se obter o controle dos corpos dos sujeitos, é o que se difunde no livro intitulado Da palavra ao gesto, de Claudine Haroche, publicado pela editora Papirus em 1998. Para tanto, o exemplar está dividido em nove capítulos que traduzem questões relacionadas ao poder, os quais inquietam e apaixonam a autora desde a sua infância.

\section{Civilidade e Polidez: Os objetos negligenciados da Ciência Política}

No capítulo um, Civilidade e Polidez: Os objetos negligenciados da Ciência Política, Haroche baseia-se em pensadores do final do século XIX e do século XX para pensar os conceitos de civilidade e polidez, e como estão atrelados à política. Nomes, como Montesquieu, Tocqueville e Rondelet são citados, a priori, a fim de traçar um forte paralelo socio-histórico, no que tange as maneiras e a civilidade bem como a compreensão dos laços políticos em momentos e regimes distintos.

Diante disso, pautada em Montesquieu, a autora afirma que as leis não podem se distanciar dos costumes que as regem. Além disso, transformar os modos e costumes por meio de leis pode parecer um tanto quanto ditatorial. Para o filósofo, a pretensão com a criação das leis era alcançar a "paz social" e a ordem, por meio de regras que reunissem os homens, ou seja, a regras de civilidade e de respeito mútuo.

Montesquieu ainda considera que o conceito de polidez seria adular o outro bem como seus defeitos, já a civilidade seria a ocultação das nossas falhas. Para tanto, cria-se uma espécie de contrato em que ambas as partes não se podem corromper.

Haroche faz uma análise das reflexões de Montesquieu e Tocqueville, na qual o segundo desdobra-se das influências de pensamento do primeiro. A autora observa que ao escrever "Da democracia na América",", Tocqueville, em meio a rascunho, não exaure o tema sobre "as maneiras americanas", uma vez que ainda não percebeu todo o significado político do tema, apenas pistas, especulações e incertezas. Porém, no texto definitivo ele supera as falhas e o aprimora, percebendo a influência do estado social e político sobre as maneiras, além do poder dos laços sociais e políticos em moldar os temperamentos.

Ademais, na mesma linha de pensamento, a autora observa que Tocqueville atenta-se ao olhar do outro (estrangeiro) em relação às regras da polidez e das maneiras, dicotomizando os que vivem as leis da democracia e os que vivem as da aristocracia.

1 Doutoranda em Análises textuais, discursivas e enunciativas pelo PPG/UFRGS

2 "Em certo sentido, pode-se dizer que o efeito da democracia não é exatamente o de dar aos homens certas maneiras, mas impedir que as tenham. " (TOCQVILLE,1990, p.185)

3 Tocqueville, De la démocratie em Amérique. Paris: Vrin, 1990. 
Observa-se que mesmo em locais de nascimento diferentes, as regras sociais precisam ser mantidas, pois quando cada homem pensa que tem o poder de decidir por si só, desde o modo de vestir, até suas convenções de linguagem, tampouco se negará a julgar tudo por si mesmo. Ocasionando assim, do simples cotidiano para a sociedade como um todo, grandes revoluções. Diante disso, é preciso formas para soldar as barreiras sociais, uma vez que não se pode mais coagir o indivíduo, e sim fazê-lo desejar o costume, a polidez e a civilidade.

Haroche, diante dos escritos de Tocqueville, questionam-se sobre a democracia: as instituições não teriam se atentado para as críticas, feitas por pensadores, desde os séculos XVII e XVIII, a respeito de como a polidez e as maneiras mascaram a realidade?

Na sequência, inquietações e críticas surgem de perguntas formuladas pela socióloga em relação à polidez e a virtude, as quais indagam a possibilidade de contribuição à felicidade alheia e o abandono de si, manifestação de uma falsidade que impede relações sociais verdadeiras ou, ainda, uma espécie de simulacro conveniente, que serve de paliativo para a ausência de virtudes sociais.

Resgatando Rondelet, posterior a Tocqueville, Haroche cita os efeitos da impolidez na sociedade francesa, criando o egoísmo e desfoque em relação ao outro. O que antes era considerado essencial, passa a ser visto como dispensável. Percebe-se o desapego das maneiras e preza-se pela sinceridade e transparência social. No entanto, como contraponto, as cerimônias religiosas, os cultos, passam a ocupar o lugar das maneiras e das regras como formas de coerção.

Para a autora, há tentativas de suprir as convenções sociais, uma vez que se confunde esfera privada, com vida pública e esfera profissional, restringindo a espontaneidade e liberdade do indivíduo.

Após tracejar essa linha histórica, a socióloga se vale de pensadores contemporâneos, como Habermas, Agulhon, Sennett, Ariès, Goodman e Roger Chartier para postular que se percebe uma desconsideração do político em relação às maneiras, pois elas refletem-se somente na vida privada e não no social como um todo.

Por fim, categoricamente, ao final do primeiro capítulo, Claudine Haroche questiona-se sobre a civilidade e a polidez. Ambas seriam detalhes ínfimos ou se revolveriam os solos mais áridos das relações/ações humanas diretamente atadas à sociologia política?

\section{Governo de si, Governo dos outros; uma questão política e antropológica}

Ao abrir o capítulo dois, Governo de si, Governo dos outros; uma questão política e antropológica, a autora ancorada em Norbert Elias ${ }^{4}$, recupera o fato de que o controle de si vai além de questões psicológicas, tratam-se de temas esquecidos pela filosofia política.

Norbert Elias, Max Weber, Foucault são evocados pela socióloga, mesmo que tratem de conceitos sob primas distintos, os quais o governo de si está intimamente ligado ao governo dos outros, dando progressão aos movimentos políticos e sociais das sociedades ocidentais.

Foi Foucault, mesmo em meio a rascunhos, que abordou com maestria, a intersecção da temática em relação à história, à teoria e ao teor político. Governar, para ele, estaria relacionado à conduta de vida dos outros.

4 Norbert Elias par lui-même. Paris: Fayard,1991. 
Dando sequência ao que foi postulado pelo autor, Gordon restringe o conceito, pautando-se na governamentalidade de si para si e de si para os outros, o que se relacionava com o controle sobre os corpos e a soberania política.

Articulada ao pensamento de Elias, Haroche afirma que o governo de si está ligado à contenção. É preciso estar em vigilância, controlar os gestos e os sentimentos em relação ao outro.

A autora destaca na obra de Elias uma menção a um trecho de Erasmo, de 1530, no qual ele discorre sobre a educação dos jovens. Seja em uma igreja, no ambiente familiar ou em um encontro, é preciso atentar para o controle dos gestos e posturas sociais, o que deve denotar decoro e decência acima de tudo.

Foi Courtin (1671), no livro intitulado de Novo tratado da civilidade que se pratica na França e alhures entre homens de bem ${ }^{5}$, que conceituou, de forma primorosa, o sentido de contenção, no qual precisa-se ter controle das paixões, depois das ações e, por fim, das palavras. Um homem possui a si porque possui seu interior, portanto precisa transparecer sereno e tranquilo.

A partir dessa conceituação, a posteriori, La Mothe le Vayer postula que a moral, ciência que trata dos costumes, educa sobre o modo de como governar a si pela razão. Para tanto, governar uma nação, advém do governo de si.

Diante da ancoragem teórica apresentada, Haroche, ao findar o capítulo, questiona-se sobre o que realmente significa contenção, se não o contraponto, os excessos, o medo do que não se pode governar em relação à integridade, à identidade e à virtude de cada sujeito. Sob essa ótica, expõe o propósito da racionalização das condutas humanas e como as regras e preceitos agregam-se aos gestos e posturas como formas de rituais, que retratam costumes de uma sociedade. Ademais, trata-se de um processo histórico que redesenha o conceito de contenção nos corpos dos sujeitos, que para além de questões psicológicas, trata-se de questões políticas.

O trabalho do poder político sobre os sentimentos e os corpos: fazer amar, respeitar o rei na monarquia absoluta no século XVII

O descontrole em relação às emoções, o não governo de si e o abandono das regras e normas sociais, é o que causa temor sobre o trabalho do poder político, sobretudo, a dominação dos sentimentos e dos corpos.

Haroche, ancorada em Ansart ${ }^{6}$, recupera o Antigo Regime, a fim de perceber como a dominação dos corpos era feita de modo velado e silencioso, partindo de uma posição hierárquica, da monarquia para seus súditos. Como forma de coerção dos corpos, havia, para tanto, a criação de um simulacro sentimental político relativo à monarquia como forma de abrandar a submissão, ou seja, institucionalizando uma domesticação dos gestos e posturas, um silenciamento.

No que tange ao silenciamento dos corpos e dos gestos dos sujeitos, naquele período histórico, os corpos, nada mais eram, que instrumentos políticos que engendravam os rituais. As posturas e os gestos eram voltados ao respeito e à imputação do medo.

5 Antoine de Courtin, Nouveau traité de la civilité qui se pratique em France et ailleurs parmi les bonnêtes gens. Paris, 1671.

6 Pierre Ansart, La gestion des passions politiques. L'Age d'Homme,1983. 
No período absolutista, a figura do cardeal Richelieu provocou um deslocamento político referente às regras e normas de etiqueta que vigoravam, uma vez que por meio dos gestos contatava-se a insubmissão ao rei. Um rosto sério ou uma inquietação corporal denunciavam situações em que se proibiam o diálogo.

Constata-se, a partir da exposição da visão na íntegra dos autores Richelieu, Luís XIV e Saint-Simon, na obra, que o Estado prima pela ordem, abominando qualquer tipo de desordem. A vigilância sempre esteve presente desde o Antigo Regime e perdura até a atualidade.

Definitivamente, o lugar social e político que se ocupa, dá permissão para a coerção e para o controle dos corpos.

Posições e precedências no cerimonial de corte: elementos para uma antropologia política

No Antigo Regime, a postura, a posição social e a ordem dicotomizam o valor do sujeito, principalmente, pela validação do julgamento do outro. Ser inferior é não ter o controle de si mesmo, comportamento julgado por monarcas como os de sujeito sem prestígio social.

Ao temer a inferioridade, adere-se às normas, aos gestos e às posturas que são subordinados. As posturas, no Antigo Regime, sempre foram foco de coerção, nesse sentido, a contribuição de Saint-Simon ${ }^{7}$, para o estudo, revela que a altura era um elemento fundante da dominação: o ato de prostrar-se e elevar-se ou reverenciar o monarca ou qualquer autoridade eram peças-chave para a dominação dos corpos.

Gestos tomados historicamente como insignificantes, eram mantidos denotando o poder político por aqueles que os executavam dentro das instituições.

\section{Gestos, posturas, movimentos: a ordem inscrita nos corpos}

A proposta da autora consiste em propor uma análise, até então desconsiderada, sobre os corpos políticos e os corpos individuais que se ligam aos diversos campos do saber: político, sociológico, jurídico e antropológico, atados à ordem e à hierarquia.

Ligado ao campo histórico e da ciência política, Sewell ${ }^{8}$, analisa as palavras ordem, corpo e Estado como polissêmicas tanto dentro quanto fora do campo social e político.

Para além da questão da ordem e Estado, destaca-se, na obra, o fato da lacuna deixada por Elias ${ }^{9}$, no qual o autor não trata do estudo dos corpos relacionados ao lugar, ou seja, à questão espacial dos corpos. A posição que um corpo social ocupa revela privilégios ou não em relação aos demais. Para tanto, o espaço central de uma sociedade é ocupado por quem tem prestígio social ou poder.

No que diz respeito à contribuição de Loyseau ${ }^{10}$, a mesma é cara a ele quando se trata da ordem preponderante do governo, uma vez que os homens comuns devem se subor-

7 Saint-Simon, Mémories (1717-1716). Col. "La Pléiade”. Vol. V. Paris: Gallimard,1985, p.50.

8 W. Sewell, "État, corps et ordre: Some notes on the social vocabular on the French Old Regime",1974.

9 N. Elias, La Société de cour. Paris: Calmann-Lévy,1975 (primeira edição 1939).

10 C. Loyseau, Traité des ordres et simples dignitez. Prefácio. 1610. 
dinar a uma figura superior ou a uma instituição. Não deve haver igualdade de posições, mas uma hierarquização entre um rei e um súdito, no Antigo Regime, assim como entre um burguês e um proletário, no século XXI.

Chega-se a uma conclusão: as bases sociais e políticas ainda estão arraigadas em regras primitivas que foram transmitidas de geração em geração, primando pela valorização da aparência. Os atributos sociais suprimem os valores humanos.

As cerimônias e os rituais de corte: instrumentos de uma política de comunicação

As palavras valem-se de uma finalidade fundamental no Antigo Regime: comunicar, porém, especificamente, o controle que advém da comunicação, e o poder que se estabelece em relação a ela. Para além das palavras, a arte de exibição também contribui para coerção dos corpos, imputação do respeito e do medo, consequentemente a manutenção de poder, hierarquização e ordem.

Ao preocupar-se com a aparência, se é amado por seus súditos, consequentemente, o bispo detém o poder, a ordem e a submissão de seus fiéis. Assim, se trajando como um simples capelão, o bispo não tem o poder que lhe é conferido socialmente, ou seja, não há devoção em suas palavras, rituais e gestos.

De forma provocativa, a autora da obra questiona-se a respeito das tradições. "Devemos falar de costumes imemoráveis, de tradições seculares, de disposições naturais ou, mas apropriadamente, de finalidade social ou política?" (HAROCHE, 1998, p. 107).

A partir da aparência, dava-se para ver o que cada indivíduo parecia ser, mas poucos conseguiram ver além disso. As formas ritualísticas não tinham outra função a não ser social e política, pois garantiam que os sujeitos não agissem segundo a sua vontade, mas que se assujeitassem ao poder do rei ou do bispo (que também estava subordinado ao rei).

A desconsideração das normas de etiqueta, das maneiras e dos rituais parecem estar destinados somente aos textos políticos.

\section{Poderes emocionais do caminhar real: os usos políticos da lentidão}

As aparências, os signos e os gestos são tomados como objetos de poder pelas instituições políticas. Os signos tais como: a coroa, as vestimentas reais, o trono, o cetro, e os adereços reais são que dicotomizam o poder: o rei e os demais membros (inferiores) da sociedade. Anexo a isso, o gesto de caminhar lentamente pela multidão também está relacionado a um signo de poder.

Ao tratar sobre gesto de caminhar, observa-se a postura que o rei adotava para tal ação: o cuidado com cada gesto, sua postura discreta, uma atitude nobre e um andar natural. Os movimentos do caminhar, também são controlados, contidos e neutros. Tem-se o controle de si e a vigilância para poder dominar os subordinados.

No que diz respeito ao descontrole de si, este pode ser verificado em uma situação de falecimento de um membro da corte. No Regime Antigo, no qual o homem está à deriva de suas ações e emoções, ele pode ser facilmente interpretado por outrem.

Para tanto, o gesto precisava ser controlado independente de qualquer situação social ou familiar, pública ou privada, pois este, para Norbert Elias, apresentava uma finalidade 
social e política. Cada gesto pode trair aquele que o produz, levando à contradição e, posteriormente, ao julgamento.

\section{Reserva nos costumes e controle da violência política: a tese de Norbert Elias}

Claudine Haroche, propõe-se, na abertura do capítulo oito, intitulado de Reserva nos costumes e controle da violência política: a tese de Norbert Elias, refletir sobre as teses cunhadas acerca da violência por Norbert Elias. No que tange à violência, afasta-se a agressividade e a violência por meio do controle social, gerando o processo de civilização.

$\mathrm{O}$ que Elias ${ }^{11}$ tenta explanar é sobre o uso da violência física como uma forma indispensável à conquista. A priori, numa prática rudimentar tinha a função de sobrevivência. A posteriori, no contexto da corte, esses meios tornar-se-iam mais refinados com menos exposições violentas e emocionais. Contudo, há uma fragmentação dos sujeitos: de um lado as resistências às repressões, de outro o medo da dependência e da coerção.

$\mathrm{Na}$ questão histórica, observa-se que a violência, na Idade Média até o Renascimento, dava-se corpo a corpo. Após esse período, a coerção passa-se face a face, no qual o governo se beneficia desse mecanismo de ação para dominar os corpos por meio de gestos e posturas.

Ao se afastar da violência física medieval, Haroche parafraseando Elias, postula que “a reserva afasta a violência física; mas também que essa mesma reserva pode perfeitamente acompanhar outras formas de violência, psicológica e simbólica, nas quais a habilidade, a prudência, a reticência, o cálculo, a manipulação e a dissimulação são essenciais." (HAROCHE, 1998, p.132). No que concerne às maneiras e à reserva, percebe-se que elas podem ter a finalidade de coibir ou desencadear a violência ou, pelo menos, acobertá-la.

Textos contemporâneos tratam do distanciamento da polidez e da civilidade nas sociedades democráticas, que trazem como ponto central a busca pela igualdade. Porém, Sennet $^{12}$, postula que a ausência de polidez e de formas ocasionariam a violência, remontando ao período medieval. Mediante a tal constatação dos autores, Haroche afirma que a polidez deriva da violência e do dever de impedi-la de existir. O excesso do governo de si, da polidez e de regras de etiqueta remetem à violência contra o próprio sujeito.

\section{A compaixão como amor social e político do outro no século XVIII}

O último capítulo do livro Da palavra ao gesto, trata da condição política da compaixão relativa aos homens do fim do século XVIII. Prima-se por uma equidade de condições, reivindicando, por parte da sociedade, igualdade e solidariedade, esta última está no centro do discurso político contemporâneo. Para tanto, apresenta-se a contribuição da filósofa Hannah Arendt.

A filósofa Arendt ${ }^{13}$, trata do papel político que a compaixão assume em relação ao outro frente ao sofrimento. Ademais, prezar pela igualdade, abominação de privilégios não dependem de questões psicológicas, mas estritamente políticas.

11 N. Elias, La civilisation des moeurs. Paris: Calmann- Lévy, 1973, p.326.

12 R. Sennet, The fall of public man. Nova York: Vintage Books, 1975.

13 Arendt, Essai sur la Révolution (On Revolution - 1963). 
O que o século XVIII propunha era o extravasamento dos sentimentos controlados pelo absolutismo. E a forma pela qual se pretendia executá-lo: compaixão pelo outro, sensibilidade ao sofrimento e ódio aos privilégios.

A sensibilidade à miséria era o que se externava nos textos literários com a finalidade de educar a sociedade a respeito das virtudes sociais e dos sentimentos morais. O que se notava é que no momento histórico, em questão, os literatos assumiram o poder, e temas como igualdade e compaixão estavam no centro das discussões. Eram textos que visavam denunciar privilégios e desigualdades, bem como uniformizar as condutas e as maneiras dos sujeitos.

Ao conceito de compaixão, fazem-se necessária duas distinções: uma de Smith, outra de Rousseau. Para Smith, "é o equilíbrio entre o amor de si, a sensibilidade por si mesmo e a sensibilidade por outrem que exige um certo controle de si mesmo."'14. Já para Rousseau, "uma compaixão que repousa sobre uma sensibilidade, um temperamento feito de espontaneidade, leva à anulação de si, que conduz, por vezes, à rebelião contra si mesmo." 15

Para tanto, a compaixão constitui ao mesmo tempo um princípio e um ideal político no final do século XVIII. Trata-se da vida pública, concomitante a privada, pois os sujeitos enxergam-se como semelhantes e quer elevar-se uma relação de equidade, em seu sentido mais amplo.

Ao finalizar a obra, a autora empreendeu um trabalho histórico, sociológico, antropológico, filosófico e político, uma vez que delineou, de modo relevante e questionador, a evolução dos modos de controle dos corpos por meio dos gestos, posturas, maneiras e virtudes, alocadas desde a Idade Média até o século XVIII, os quais vigoram até a atualidade.

Referências

HAROCHE, C. Da palavra ao gesto. Campinas: Papirus, 1998.

Recebido em: 31/05/2019; Aceito em: 21/06/2019

14 A. Smith, Théorie des sentiments moraux. Paris: Guillaumin, 1860.

15 J.J. Rousseau, Discours sur l'origine et les fondements de l'inégalité parmi les hommes. GF Flammarion, 1971 (1974). 